\title{
Experimental Study of the Thermal Effect of the Dissolution Reaction for Some Alkalis and Salts with Natural Mixing and Forced Stirring
}

\author{
Sergii Bespalko *, Oleksii Halychyi, Mykhailo Roha, Sviatoslav Poliakov, Genadiy Kaleinikov, and Taisiia Naumenko \\ Cherkasy State Technological University, Department of Energy Technologies, Shevchenko Boulevard, 460, 18006 Cherkasy, Ukraine
}

\begin{abstract}
The paper presents the results of an experimental study of the exothermal and endothermal effects occurring on the dissolution of potassium nitrate $\mathrm{KNO}_{3}$, ammonium nitrate $\mathrm{NH}_{4} \mathrm{NO}_{3}$, potassium hydroxide $\mathrm{KOH}$ and sodium hydroxide $\mathrm{NaOH}$, in distilled water with natural mixing and forced stirring. It is shown that for natural mixing, $\mathrm{NH}_{4} \mathrm{NO}_{3}$ and $\mathrm{KOH}$ are the most appropriate working substances for cooling and heat generation respectively, while for forced stirring, $\mathrm{NH}_{4} \mathrm{NO}_{3}$ and $\mathrm{NaOH}$ display better performance. The optimal concentrations of the liquid solutions for achieving extreme temperatures and maximal enthalpy changes are also defined. In addition, the regression function and regression coefficients describing correlations between the total enthalpy change of the calorimetric system and the solution concentration are found, for the most suitable liquid solutions. The experimental results obtained can be used to develop generating reactors for exothermal heating and endothermal cooling for a thermochemical seasonal storage system able to store solar heat or heat from combined heat and power (CHP) units of biogas plants in summer, for heating purposes in winter, while generating cooling to support air conditioning systems in summer.
\end{abstract}

\section{Introduction}

Recently, much research attention has been paid to the development of thermochemical heat storage systems, which may store the greatest amount of heat. Comprehensive reviews of the heat storage technology and the materials used are presented in [1-3]. However, according to Sole et al. [4], the main issue limiting the adoption of this technology was found to be the behavior of the working substances within the thermochemical reactor. Therefore, characterization of the working substances and the reactions occurring in thermochemical reactors will play a significant role in developing efficient heat storage systems.

In this experimental research, we have focused our attention on studying the dissolution reaction of chemicals in water, for substances that produce significant exothermal heat release and endothermal heat absorption, especially potassium hydroxide $\mathrm{KOH}$, sodium hydroxide $\mathrm{NaOH}$, ammonium nitrate $\mathrm{NH}_{4} \mathrm{NO}_{3}$ and potassium nitrate $\mathrm{KNO}_{3}$. The aim of our experiments was to study (1) the influence of the solution concentration on the solution temperature and enthalpy changes and (2) the influence of non-stirring and forced stirring on the thermal effect of the above-mentioned dissolution reactions, in order to find a suitable pair of working substances, as well as their concentrations, for a thermochemical heat storage and cooling generation system projected.

\section{Experimental setup and measurement techniques}

\subsection{Description of the experimental setup and measuring equipment}

A schematic and a photo of the experimental facility used to measure solution temperature change in the dissolution of alkalis and salts in water, are shown in Fig. 1 a and Fig. 1 b respectively. The setup included an insulated box (calorimeter) with a chemical test tube inside made of borosilicate glass, containing the solute. The tube was sealed by a rubber plug with three holes through it, used for the purposes of (1) distilled water inlet, (2) air outlet and (3) temperature sensor installation. In the experiments, the solution temperature was measured and automatically recorded using a measuring system consisting of (1) a HEL-705 (Honeywell) platinum temperature sensor calibrated with an accuracy of $\pm 0.5 \mathrm{~K}$ and installed in a hollow pipe made of 316 stainless steel, (2) a WAD-AMAX (Acon) signal amplifier, (3) a WAD-AD-12-128HL (Acon) data logger and (4) a personal computer. To ensure a good thermal contact between the internal surface of the metal pipe and the temperature sensor, the former was filled with glycerin. The data acquisition frequency was set at $1 \mathrm{~Hz}$.

Two types of experiments were conducted for each of the solutes. The first type consisted of measuring the

\footnotetext{
* Corresponding author: $\underline{\text { s.bespalko@,chdtu.edu.ua }}$
} 
temperature change of the solution when water was added to the solute without applying forced stirring, hereinafter called natural mixing. The second type was intended to

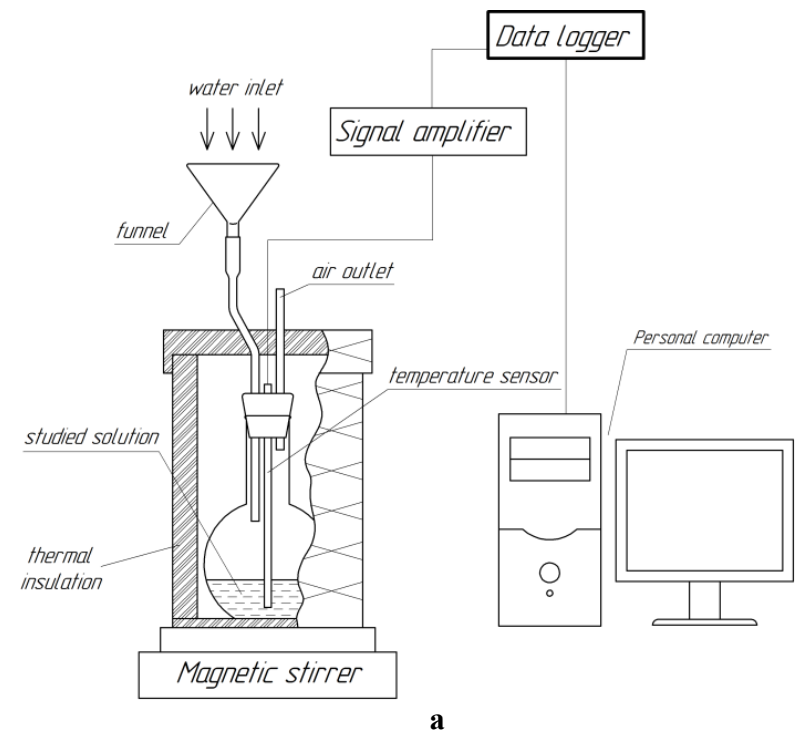

assess the influence of forced stirring on the solution temperature change. For forced stirring, a MM-5 (Ekochim) magnetic stirrer was used.

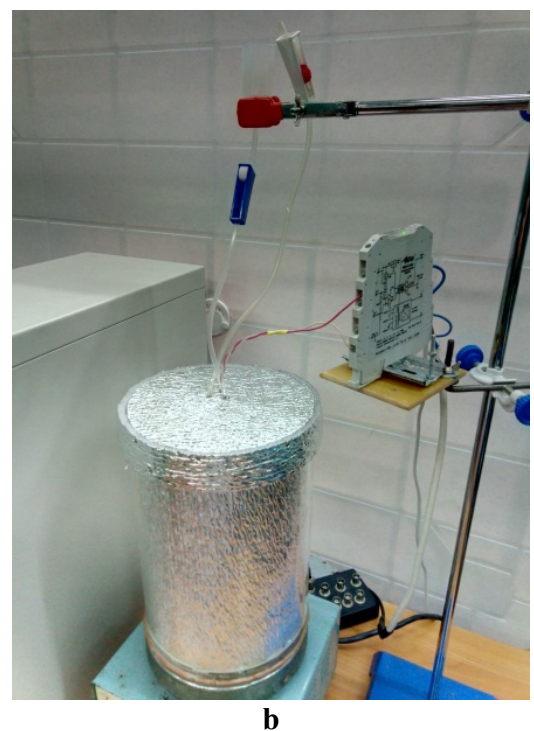

Fig. 1. Experimental setup: $\mathbf{a}$ - scheme of the experimental setup, $\mathbf{b}$ - photo of the experimental setup.

Distilled water was used as the solvent, while as the solute we tested four chemicals: two alkalis $-\mathrm{KOH}$ and $\mathrm{NaOH}$, which produce significant exothermal heat release and two salts $-\mathrm{NH}_{4} \mathrm{NO}_{3}$ and $\mathrm{KNO}_{3}$, which produce considerable endothermal heat absorption. The distilled water was produced in our laboratory using a DE-4-2M (SZMO) distillation apparatus.

In each experiment, the initial temperature of the solutes and solvent was $10^{\circ} \mathrm{C}$. The pressure inside the test tube was equal to the atmospheric pressure $\mathrm{P}=101 \mathrm{kPa}$. The total mass of the solution obtained in each experiment, i.e., solvent plus solute, was $150 \mathrm{~g}$. The mass of the solute and solvent was measured using a FEN-300L (Dneproves) high-accuracy weighing machine.

\subsection{Experimental procedure}

The experimental procedure for studying the thermal effect of the dissolution reaction was as follows.

The glass test tube was first filled with the solute, sealed with a rubber plug and then installed in the insulated box. The data logger was triggered before adding the distilled water. The data acquisition system recorded the temperature of the solution formed over time. Five separate experiments were conducted to define the average values of the temperatures measured. Finally, Mathcad 15 was used for data processing and presenting the collected data using graphical representations.

The solution temperature change was measured for each of the solutes at varying concentrations from 10 mass $\%$ to 80 mass \%. In the experiments with forced stirring, a magnetic stir bar was placed in the test tube before filling with the solute.

\subsection{Procedure for calculating the enthalpy changes of the solutions}

When calculating the enthalpy changes of the solutions, the following assumptions were made: (1) that the thermodynamic system under study was adiabatic, (2) that the liquid solution formed was a homogeneous mixture with a uniform temperature distribution throughout the volume, (3) that the specific heat capacity of the liquid solution is an additive property of the mixture and (4) that the enthalpy of mixing is zero.

To determine the specific enthalpy changes of solutions, hereinafter referred to as enthalpy changes, values of the solution temperature changes were used, which in turn were found from the temperature-time diagrams, as shown in Fig. 2 a and Fig. 2 b for endothermal and exothermal reactions respectively. Finally, the enthalpy change was calculated as the difference between maximal/minimal and initial solution enthalpies:

$$
\Delta h_{s o l}=h_{2}-h_{1},\left[\frac{k J}{k g}\right],
$$

where, $h_{1}$ is the solution enthalpy at the initial temperature $t_{1}$ and $h_{2}$ is the solution enthalpy at the maximal/minimal temperature $t_{2}$, for exothermal and endothermal reactions respectively.

The total enthalpy change of the calorimetric system was found as the sum of the enthalpy change of the solution $\Delta h_{\text {sol }}$ and the enthalpy change of the experimental sample setup consisting of borosilicate glass, 316 stainless steel and glycerin:

$$
\Delta h_{\text {total }}=\Delta h_{\text {sol }}+\Delta h_{\text {glass }}+\Delta h_{\text {steel }}+\Delta h_{\text {glyc }},
$$

where, $\Delta h_{\text {glass }}$ is the enthalpy change of the glass test tube, $\Delta h_{\text {steel }}$ is the enthalpy change of the stainless steel hollow pipe and $\Delta h_{g l y c}$ is the enthalpy change of the glycerin. 

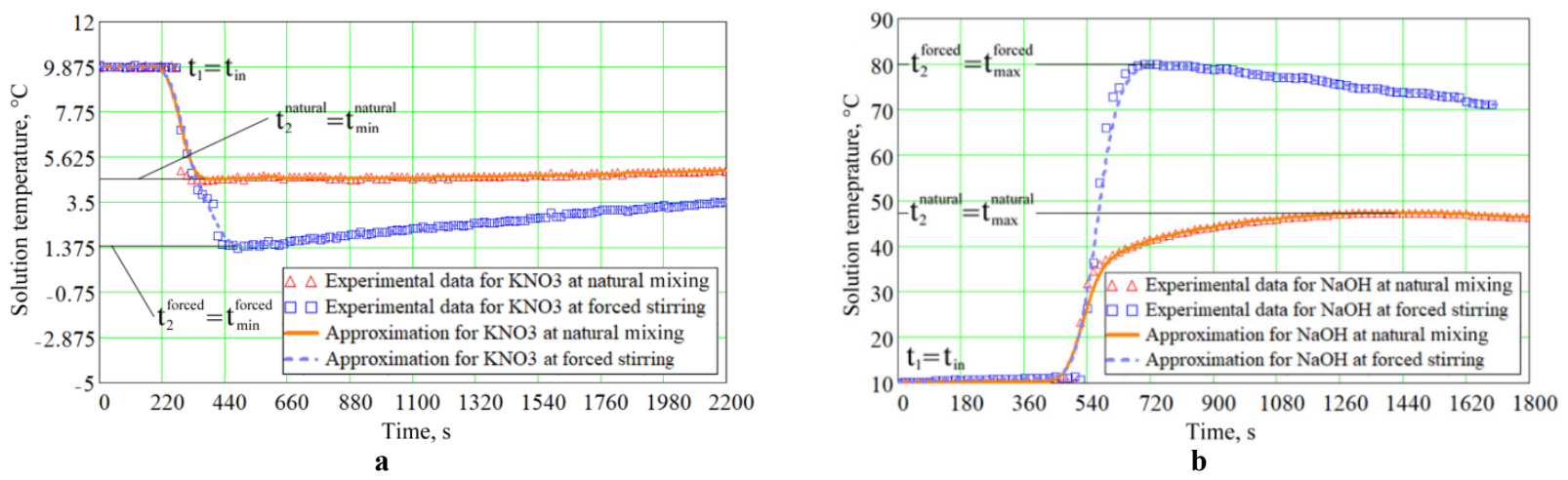

Fig. 2. Examples of temperature-time diagrams for the endothermal and exothermal dissolution reactions: $\mathbf{a}-60 \% \mathrm{KNO}_{3}$ solution, $\mathbf{b}-40 \% \mathrm{NaOH}$ solution.

The enthalpy change of the borosilicate glass was estimated as follows:

$$
\Delta h_{\text {glass }}=c_{p}^{\text {glass }} \cdot\left(t_{2}-t_{1}\right),
$$

where, $c_{p}^{\text {glass }}$ is the specific heat of the borosilicate glass at $25^{\circ} \mathrm{C}, c_{p}^{\text {glass }}=830 \frac{\mathrm{J}}{\mathrm{kg} \cdot \mathrm{K}}[5]$.

The enthalpy change of the stainless steel was calculated as follows:

$$
\Delta h_{\text {steel }}=c_{p}^{\text {steel }} \cdot\left(t_{2}-t_{1}\right)
$$

where, $c_{p}^{\text {steel }}$ is the specific heat of the 316 stainless steel in the temperature range $0-100^{\circ} \mathrm{C}, c_{p}^{\text {steel }}=500 \frac{\mathrm{J}}{\mathrm{kg} \cdot \mathrm{K}}$ [6].

The enthalpy change of the glycerin was estimated as follows:

$$
\Delta h_{g l y c}=c_{p}^{g l y c} \cdot\left(t_{2}-t_{1}\right),
$$

where, $c_{p}^{g l y c}$ is the specific heat of the glycerin at $25^{\circ} \mathrm{C}, c_{p}^{g l y c}=2416 \frac{\mathrm{J}}{\mathrm{kg} \cdot \mathrm{K}}[7]$.

The solution enthalpy at the initial temperature was defined as the sum of solvent and solute enthalpies, as shown below:

$$
h_{1}=c_{p}^{\text {solute }} \cdot t_{1}+c_{p}^{\text {solvent }} \cdot t_{1}
$$

where, the first term is the enthalpy of the solute and the second term represents the enthalpy of the solvent at the initial temperature $t_{1}, c_{p}^{\text {solute }}$ is the isobaric specific heat capacity of the solute at $t_{1}, c_{p}^{\text {solvent }}$ is the isobaric specific heat capacity of the solvent at $t_{1}$ and $t_{1}$ is the initial temperature of the solvent and solute.

The solution enthalpy at the maximal/minimal temperature was calculated as follows:

$$
h_{2}=c_{p}^{\text {solution }} \cdot t_{2}
$$

where, $c_{p}^{\text {solution }}$ is the isobaric specific heat capacity of the solution and $t_{2}$ is the maximal temperature of the solution for the exothermal reaction or the minimal temperature of the solution for the endothermal reaction.

According to [8], the specific heat capacity of the liquid solution is defined as an additive property, i.e.:

$$
c_{p}^{\text {solution }}=\left[c_{p}^{\text {solute }} \cdot g+c_{p}^{\text {solvent }} \cdot(1-g)\right],
$$

where, $c_{p}^{\text {solute }}$ is the isobaric specific heat capacity of the solute at $t_{2}, c_{p}^{\text {solvent }}$ is the isobaric specific heat capacity of the solvent at $t_{2}$ and $g$ is the mass fraction of the solute.

The specific heat capacities of solutes and solvent as a function of temperature were estimated as shown below:

- For $\mathrm{KOH}$, the following formula was applied:

$$
c_{p}^{\text {solute }}=\frac{c_{p m o l a r}^{K O H}}{M_{K O H}}
$$

where, $c_{\text {pmolar }}^{\mathrm{KOH}}$ is the molar specific heat capacity of $\mathrm{KOH}$ at constant pressure and $M_{\mathrm{KOH}}$ is the molar mass of $\mathrm{KOH}, M_{\mathrm{KOH}}=40 \cdot 10^{-3} \frac{\mathrm{kg}}{\mathrm{mole}}$.

In turn, the molar specific heat capacity of $\mathrm{KOH}$ in the temperature range $50-522 \mathrm{~K}$ was calculated using the following expression [9]:

$c_{\text {pmolar }}^{\mathrm{KOH}}=-4.1+4.687 \cdot 10^{-1} \cdot t-1.0706 \cdot 10^{-3}$.

$t^{2}+9.42 \cdot 10^{-7} \cdot t^{3}$

where, $t$ is the temperature.

- For $\mathrm{NaOH}$, the following expression was applied:

$$
c_{p}^{\text {solute }}=\frac{c_{\text {pmolar }}^{\mathrm{NaOH}}}{M_{\mathrm{NaOH}}}
$$

where, $c_{\text {pmolar }}^{\mathrm{NaOH}}$ is the molar specific heat capacity of $\mathrm{NaOH}$ at constant pressure and $M_{\mathrm{NaOH}}$ is the molar mass of $\mathrm{NaOH}, M_{\mathrm{NaOH}}=56.1 \cdot 10^{-3} \frac{\mathrm{kg}}{\mathrm{mole}}$.

In turn, the molar specific heat capacity of $\mathrm{NaOH}$ in the temperature range $60-592 \mathrm{~K}$ was calculated using the following expression [9]:

$$
\begin{aligned}
& c_{\text {pmolar }}^{\mathrm{NaOH}}=-31.8+8.455 \cdot 10^{-1} \cdot t-3.0665 \cdot 10^{-3} \\
& t^{2}+5.0706 \cdot 10^{-6} \cdot t^{3}-2.92 \cdot 10^{-9} \cdot t^{4},
\end{aligned}
$$

where, $t$ is the temperature.

- For $\mathrm{NH}_{4} \mathrm{NO}_{3}$, the isobaric specific heat capacity was calculated using two formulae [10]:

- in the temperature range $-50-(-16.9)^{\circ} \mathrm{C}$ :

$$
c_{p}^{\text {solute }}=1.722+5.453 \cdot 10^{-3} \cdot t,
$$


- in the temperature range $-16.9-32.2^{\circ} \mathrm{C}$ :

$$
c_{p}^{\text {solute }}=1.625+4.714 \cdot 10^{-3} \cdot t .
$$

- For $\mathrm{KNO}_{3}$, the specific heat capacity was found by interpolation of the tabular data presented in [11].

- For $\mathrm{H}_{2} \mathrm{O}$, the following expression was used to calculate its isobaric specific heat capacity in the temperature range $0-100^{\circ} \mathrm{C}[12]$ :

$$
c_{p}^{\text {solvent }}=4223.6+1.075 \cdot t \cdot \ln \left(\frac{t}{100}\right),
$$

where, $t$ is the temperature.

\section{Results and discussion}
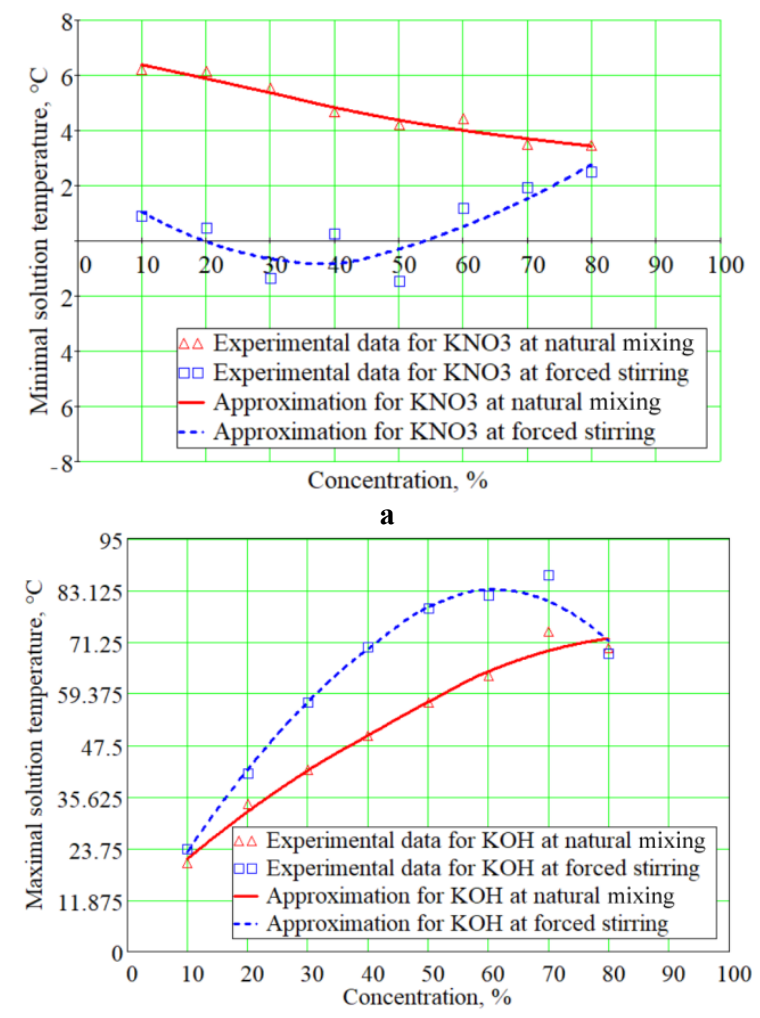

c
Examples of reaction coordinate diagrams of temperature versus time for $\mathrm{KNO}_{3}$ and $\mathrm{NaOH}$ solutions are presented in Fig. 2 a and Fig. 2 b respectively. As was expected, in the dissolution reaction of alkalis in water, exothermal heat is released, resulting in a significant increase in the solution temperature, while the dissolution of salts generates cooling, resulting in a decrease in the solution temperature. Moreover, for all the chemicals under study, the use of forced stirring had a significant effect of increasing the exothermal heat release and endothermal heat absorption, which can be explained by better mixing of solute and solvent compared to the case of dissolution without stirring. In addition, forced stirring fosters the solubility of solutes, bringing forward the onset of extreme temperatures.

Diagrams of the extreme temperatures achieved versus solution concentrations, for $\mathrm{KNO}_{3}, \mathrm{NH}_{4} \mathrm{NO}_{3}, \mathrm{KOH}$ and $\mathrm{NaOH}$, are shown in Figs $\mathbf{3} \mathbf{a}, \mathbf{b}, \mathbf{c}$ and $\mathbf{d}$ respectively.

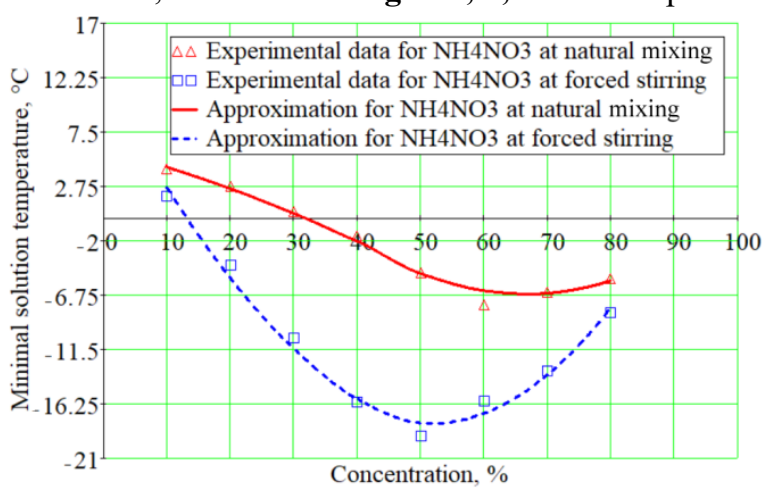

b

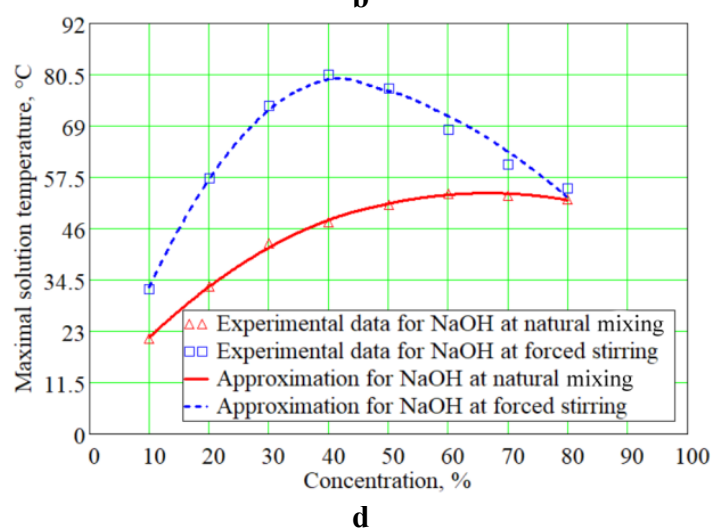

d

Fig. 3. Extreme temperatures achieved in the dissolution reactions versus solution concentrations: $\mathbf{a}-\mathrm{KNO}_{3}$ solution, $\mathbf{b}-\mathrm{NH}_{4} \mathrm{NO}_{3}$ solution, $\mathbf{c}-\mathrm{KOH}$ solution and $\mathbf{d}-\mathrm{NaOH}$ solution.

From the $\mathrm{KNO}_{3}$ temperature-concentration diagram shown in Fig. 3 a, it can be seen that for natural mixing, an increase in the solution concentration results in a decrease in the solution temperature. In this case, the relationship between the minimal temperature achieved and the solution concentration is almost linear. However, dissolution of $\mathrm{KNO}_{3}$ in water shows a slight endothermal effect. Here, the lowest temperature achieved is $+3.5^{\circ} \mathrm{C}$, at $70 \%$ solution concentration.

In contrast to the $\mathrm{KNO}_{3}$ solution, for natural mixing $\mathrm{NH}_{4} \mathrm{NO}_{3}$ shows a much better endothermal effect, resulting in a more significant drop in the solution temperature (see Fig. 3 b). Thus, the lowest temperature achieved was $-7.6^{\circ} \mathrm{C}$ at $60 \%$ solution concentration.
Furthermore, the relationship between the minimal temperature reached and the solution concentration is nonlinear.

Forced stirring for both liquid solutions, increases the endothermal effect, as shown in Figs 3 a and $\mathbf{3}$ b. Thus, for $\mathrm{KNO}_{3}$, the lowest temperature achieved is $-1.5^{\circ} \mathrm{C}$ at $50 \%$ solution concentration, whereas for $\mathrm{NH}_{4} \mathrm{NO}_{3}$ the lowest temperature reached is $-19.1{ }^{\circ} \mathrm{C}$ at $50 \%$ solution concentration. It is interesting to note that for forced stirring, the maximal endothermal effect for $\mathrm{NH}_{4} \mathrm{NO}_{3}$ liquid solution is observed at $50 \%$ solution concentration, while without stirring, the optimal concentration is $60 \%$. 
Thus, in terms of the lowest temperature achieved, $\mathrm{NH}_{4} \mathrm{NO}_{3}$ can be regarded as a promising working substance for both mixing conditions.

As can be observed from the temperatureconcentration diagrams shown in Figs $3 \mathbf{c}$ and $\mathbf{3}$ d, the dissolution reactions of $\mathrm{KOH}$ and $\mathrm{NaOH}$ in water are accompanied by considerable heat release, which results in a significant temperature change in the solutions formed. Thus, for the $\mathrm{KOH}$ solution, the optimal concentration for both mixing conditions is $70 \%$, with a temperature increase of up to $+73.6^{\circ} \mathrm{C}$ and $+86.5^{\circ} \mathrm{C}$ for natural mixing and forced stirring respectively. For the $\mathrm{NaOH}$ solution, with natural mixing the maximal solution

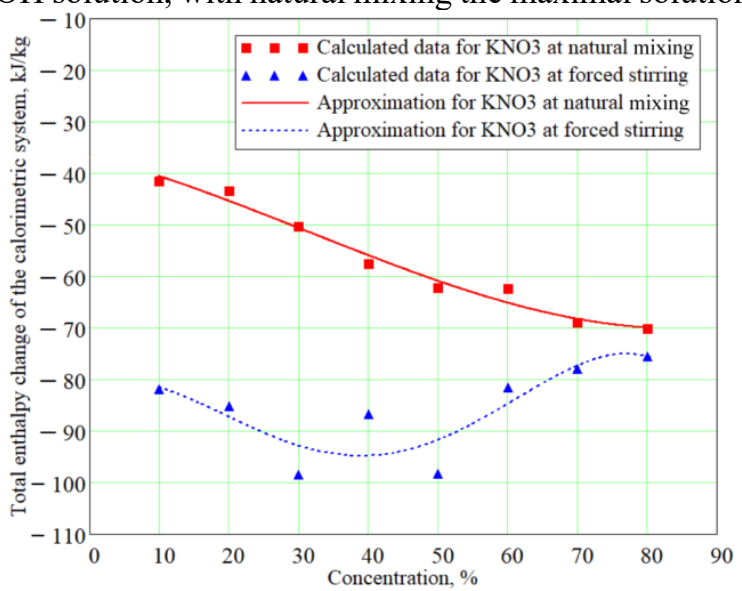

a

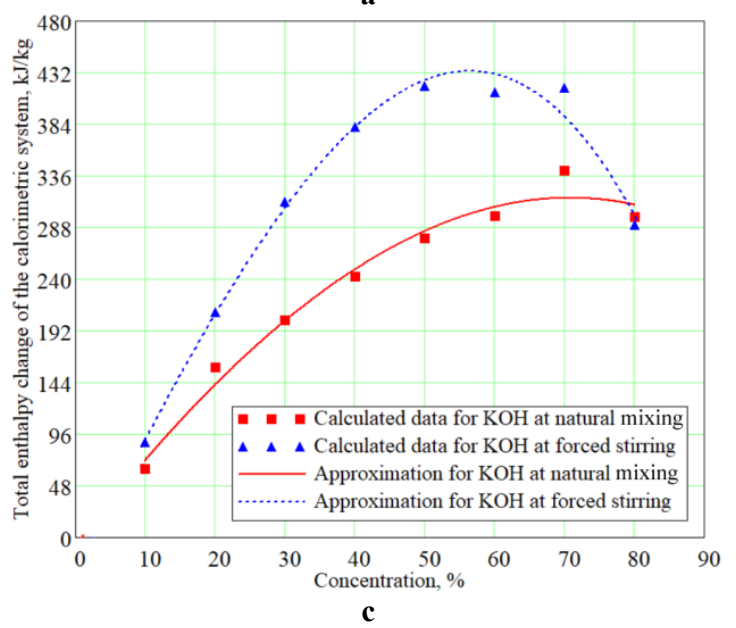

temperature achieved is $+53.9^{\circ} \mathrm{C}$ at $60 \%$ solution concentration, while for forced stirring it is $+80.5^{\circ} \mathrm{C}$ at $40 \%$ solution concentration.

Along with values of the minimal and maximal temperatures achieved in the endothermal and exothermal dissolution reactions, solution enthalpy changes also play a significant role, since they give a practical definition of the specific storage capacities of the heat storage and cooling generation reactors.

Figs $4 \mathbf{a}, \mathbf{b}, \mathbf{c}$ and $\mathbf{d}$ show the total enthalpy changes of the calorimetric system versus solution concentrations.
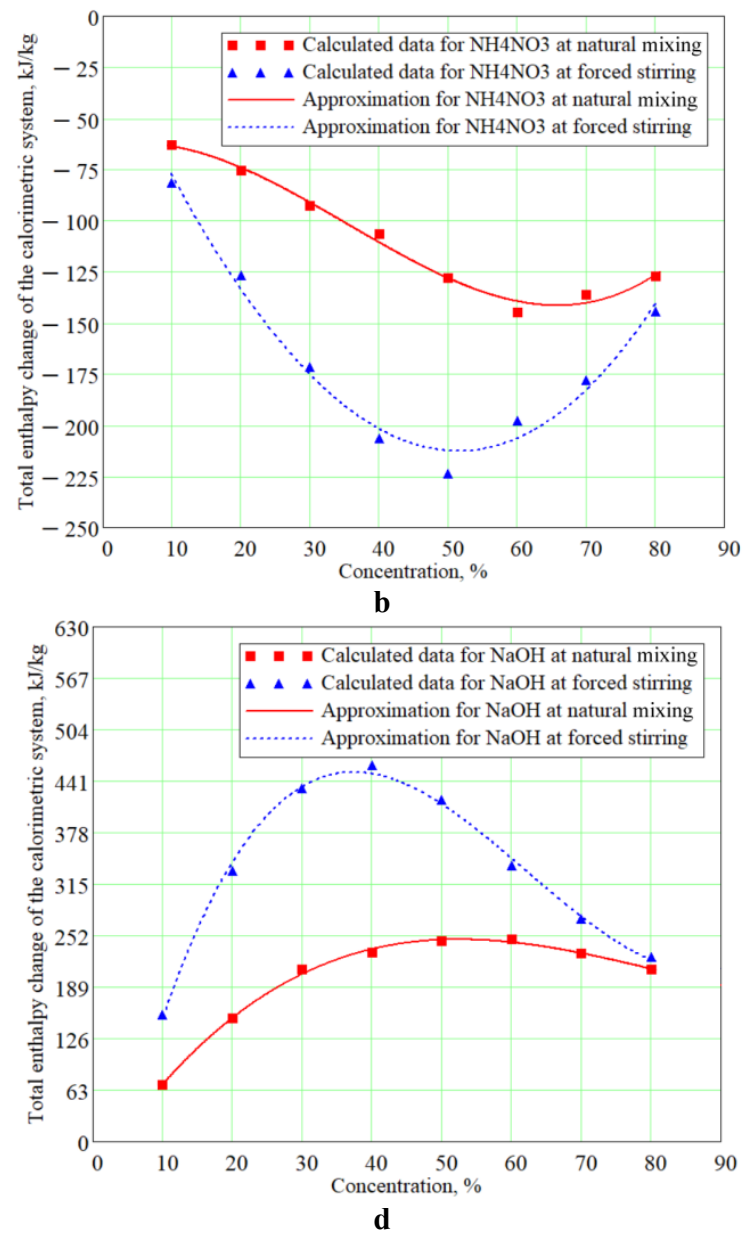

Fig. 4. Total enthalpy changes of the calorimetric system versus solution concentrations:

$\mathbf{a}-\mathrm{KNO}_{3}$ solution, $\mathbf{b}-\mathrm{NH}_{4} \mathrm{NO}_{3}$ solution, $\mathbf{c}-\mathrm{KOH}$ solution and $\mathbf{d}-\mathrm{NaOH}$ solution.

Here, a negative sign "-" signifies endothermal heat absorption, whereas a positive sign "+" signifies exothermal heat release.

Comparing enthalpy-concentration diagrams for the $\mathrm{KNO}_{3}$ and $\mathrm{NH}_{4} \mathrm{NO}_{3}$ solutions presented in Fig. 4 a and Fig. 4 b, it can be seen that with respect to the enthalpy change, $\mathrm{NH}_{4} \mathrm{NO}_{3}$ shows much better endothermal performance, since it can generate 2.1 and 2.3 times more cooling under natural and forced mixing conditions respectively. Thus, for natural mixing, the maximal endothermal heat absorption is about $-144.7 \mathrm{~kJ} / \mathrm{kg}$ at $60 \%$ solution concentration, while for forced stirring, the maximal endothermal heat absorption is about -223.5 $\mathrm{kJ} / \mathrm{kg}$ at $50 \%$ solution concentration. That is to say, the use of forced stirring in the projected endothermal reactor may increase the cooling generation by $54 \%$, together with a reduction of $10 \%$ in the $\mathrm{NH}_{4} \mathrm{NO}_{3}$ mass needed.
Comparing enthalpy-concentration diagrams for the $\mathrm{KOH}$ and $\mathrm{NaOH}$ solutions illustrated in Fig. $4 \mathbf{c}$ and Fig. $4 \mathbf{d}$, it can be seen that for natural mixing, the dissolution of $\mathrm{KOH}$ in water generates the maximal exothermal heat of $340.9 \mathrm{~kJ} / \mathrm{kg}$ at $70 \%$ solution concentration, while the dissolution of $\mathrm{NaOH}$ is accompanied by a release of 247.3 $\mathrm{kJ} / \mathrm{kg}$ of exothermal heat at $60 \%$ solution concentration. Therefore, for natural mixing, the dissolution of $\mathrm{KOH}$ generates 38\% more heat than the dissolution of $\mathrm{NaOH}$. However, under forced mixing conditions, $\mathrm{NaOH}$ displays better performance: $460.8 \mathrm{~kJ} / \mathrm{kg}$ of exothermal heat is released at $40 \%$ solution concentration versus $419.9 \mathrm{~kJ} / \mathrm{kg}$ of exothermal heat released at $50 \%$ solution concentration for $\mathrm{KOH}$. Thus, in terms of the solution 
enthalpy change, $\mathrm{KOH}$ is more appropriate for exothermal heat generation with natural mixing, while $\mathrm{NaOH}$ is more suitable with forced stirring.

It also should be noted that, despite the fact that the highest temperature is achieved for the dissolution of $\mathrm{KOH}, \mathrm{NaOH}$ generates greater enthalpy changes, even at lower temperatures, which can be explained by the higher specific heat capacity of $\mathrm{NaOH}$.

In addition to the diagrams produced, a regression function with regression coefficients was defined for each

Table 1. Regression coefficients for the function describing the correlation between the total enthalpy change of the calorimetric system and the solution concentration.

\begin{tabular}{|c|c|c|c|c|c|c|}
\hline \multirow{3}{*}{$\begin{array}{c}\text { Regression } \\
\text { coefficients }\end{array}$} & \multicolumn{2}{|c|}{$\mathbf{N H}_{\mathbf{4}} \mathbf{N O}_{\mathbf{3}}$} & \multicolumn{2}{c|}{ KOH } & \multicolumn{2}{c|}{ NaOH } \\
\cline { 2 - 7 } & \multicolumn{2}{|c|}{ mixing conditions } & \multicolumn{2}{c|}{ mixing conditions } & \multicolumn{2}{c|}{ mixing conditions } \\
\cline { 2 - 7 } & \multicolumn{2}{|c|}{ natural } & forced & \multicolumn{2}{c|}{ natural } & \multicolumn{2}{c|}{ forced } & \multicolumn{2}{c|}{ natural } & accuracy \\
\cline { 2 - 7 } & $\mathbf{9 9 . 4 \%}$ & $\mathbf{9 8 . 9 \%}$ & $\mathbf{9 8 . 8 \%}$ & $\mathbf{9 9 . 4 \%}$ & $\mathbf{9 9 . 8 \%}$ & $\mathbf{9 9 . 7 \%}$ \\
\hline $\mathbf{a}_{0}$ & -64.293 & -7.843 & -7.593 & -35.85 & -43.236 & -167.9 \\
\hline $\mathbf{a}_{1}$ & 0.748 & -7.606 & 8.458 & 12.983 & 13.107 & 38.726 \\
\hline $\mathbf{a}_{2}$ & -0.076 & 0.063 & -0.045 & -0.018 & -0.183 & -0.741 \\
\hline $\mathbf{a}_{3}$ & $7.154 \cdot 10^{-4}$ & $1.359 \cdot 10^{-4}$ & $-1.364 \cdot 10^{-4}$ & $-1.152 \cdot 10^{-3}$ & $7.326 \cdot 10^{-4}$ & $3.968 \cdot 10^{-3}$ \\
\hline
\end{tabular}

\section{Conclusions}

In this paper, an experimental study has been carried out with the aim of investigating the thermal effects occurring in the dissolution of some alkalis and salts in water, under natural mixing and forced stirring conditions. On the basis of the results obtained, the following conclusions can be drawn.

- For endothermal cooling generation, $\mathrm{NH}_{4} \mathrm{NO}_{3}$ is the most suitable solute, since the dissolution of $\mathrm{NH}_{4} \mathrm{NO}_{3}$ in water can produce significant endothermal heat absorption accompanied by a considerable solution temperature drop. Thus, for natural mixing, the maximum cooling generation occurs at $60 \%$ solution concentration with a temperature drop of up to $-7.6^{\circ} \mathrm{C}$, with $-144.7 \mathrm{~kJ} / \mathrm{kg}$ of heat absorbed. With forced stirring, the maximal endothermal effect is observed at $50 \%$ solution concentration with a temperature drop of up to $-19.1^{\circ} \mathrm{C}$ and $-223.5 \mathrm{~kJ} / \mathrm{kg}$ of cooling generated.

- Under natural mixing conditions, $\mathrm{KOH}$ is more appropriate for exothermal heat generation, as the dissolution of $\mathrm{KOH}$ in water increases the solution temperature by up to $+73.6^{\circ} \mathrm{C}$ and releases $340.9 \mathrm{~kJ} / \mathrm{kg}$ of exothermal heat at $70 \%$ solution concentration. Under forced stirring conditions, $\mathrm{NaOH}$ displays better performance, with a temperature rise of up to $+80.5^{\circ} \mathrm{C}$ and $460.8 \mathrm{~kJ} / \mathrm{kg}$ of exothermal heat released at $40 \%$ solution concentration.

The experimental results obtained in this study will be used to improve the design and efficiency of exothermal heating and endothermal cooling generation reactors in thermochemical storage systems. We also intend to study the heating and cooling generation abilities of these pairs of working substances under vacuum conditions. of the solutions and mixing conditions, as given below. For this purpose, the optimized Levenberg-Marquardt method in Mathcad 15 was applied.

$$
\Delta h_{\text {total }}=a_{0}+a_{1} \cdot c+a_{2} \cdot c^{2}+a_{3} \cdot c^{3},
$$

where, $c$ is the solution concentration $(\mathrm{m} \%)$ and $a_{0}$, $a_{1}, a_{2}$ and $a_{3}$ are the regression coefficients, with values as presented in Table $\mathbf{1}$. 